\title{
Impact of gestational diabetes mellitus in maternal and fetal health: An update
}

\author{
Sonila Alia ${ }^{2}$, Sofia Pugnaloni ${ }^{2}$, Francesca Borroni ${ }^{2}$, Laura Mazzanti ${ }^{2}$, Stefano Raffaele Giannubilo ${ }^{1}$, Andrea Ciavattini ${ }^{*}$ and Arianna Vignini $^{2}$ \\ ${ }^{1}$ Department of Clinical Sciences, Unit of Obstetrics and Gynecology, Università Politecnica delle Marche, Via Corridoni, 60124 Ancona, Italy \\ ${ }^{2}$ Department of Clinical Sciences, Section of Biochemistry, Biology and Physics, Università Politecnica delle Marche, Via Tronto 10/A, 60126 Ancona, Italy
}

\begin{abstract}
In recent years, there has been an increased incidence of gestational diabetes (GDM), defined as any degree of glucose intolerance with the onset or first recognition during pregnancy with or without remission after the end of pregnancy. The most significant risk factors are: age $>25$ years, obesity, high parity, family history of DM, past history of GDM or macrosomic infant. GDM therapy should be based on a healthy diet, exercising and glycemic control, with or without insulin. The presence of GDM has important implications for both the baby and the mother. As regard baby complications, GDM is associated with a significantly increased risk of macrosomia, shoulder dystocia, birth injuries as well as neonatal hypo glycemia and hyperbilirubinemia, genetic risk for the development of obesity, diabetes and/or metabolic syndrome in childhood. As regard mother complications, GDM is a strong risk factor for the development of permanent diabetes later in life (40\% in 10 subsequent years) and GDM in successive pregnancies (35\%), stress urinary incontinence and mixed urinary incontinence, doubled risk for overactive bladder during premenopausal period, cardiovascular morbidity. This review briefly examine the risk factors, diagnostic criteria, best therapy and management, short and long term complications for the mother and the fetus associated with such pathology.
\end{abstract}

\section{Introduction}

The classification of diabetes mellitus (DM), according to the World Health Organization (WHO), is as follows: DM type 1, DM type 2, other rare types of DM and GDM [1].

In later years, there has been an increased incidence of gestational diabetes mellitus (GDM) [2]. GDM is the most common complication of pregnancy, with important effects on maternal and fetal health, even years after delivery. GDM is defined, according to the American Diabetes Association (ADA), as a diabetes that is first diagnosed during pregnancy that is not clearly overt diabetes before gestation [3]. GDM is associated with increased risk of maternal and perinatal complication [4] with short and long-term effects [5]. An adequate and early treatment of maternal hyperglycemia leads to the reduction of the risks in mothers with GDM. It is important to understand when and how to screen these women for future manage, even if there are no universal guidelines [6]. Currently, there is a growing interest in lifestyle change and in particular more physical activity (PA), changes in dietary patterns and maintaining a healthy body weight aimed at achieving and maintaining euglycemia through the consumption of adequate meal portions, the distribution of carbohydrates and consumption of foods with a lower glycemic index $[7,8]$.

\section{The prevalence of GDM}

The prevalence of GDM has been estimated variably between $3 \%$ and $14 \%$, depending on the method used for both the diagnosis and the study population [9]. An exclusively high prevalence was detected in Zuni Indian women (14.3\%), Chinese women, Indian-born women in Melbourne-Australia (13.9\% and 15\%, respectively), and Asian women in Illawara-Australia (11.9\%) [10]. A meta-analysis of 1,770.63 participants in 40 different studies conducted by Eades et al. [11] reported that in Europe, Italy has the highest prevalence of GDM (10\%) and Sweden the lowest (1.5\%). A 1997 study has indeed underlined that different ethnic groups, in the same environmental setting, have widely variable risk [12]. However, the differences in approaches used across different studies, methods of screening, and diagnostic criteria make it difficult to understand if this marked ethnic and geographical variation causes true differences in the prevalence of GDM [13,14]. For example, a study has taken into account the ethnicity as well as the maternal age and the degree of obesity in comparison with the prevalence of GDM in different populations. The adjusted relative risk for GDM was higher in black [1.81, 95\% confidence interval (CI) 1.13, 2.89], and Hispanic $[2.45,95 \%$ CI $1.48,4.04]$ women than in white women [15].

\section{Inflammation in GDM}

GDM and DM2 share many pathophysiological characteristics and, above all, insulin resistance (IR), thus they are closely associated [1]. The balance between adequate insulin secretion and insulin sensitivity maintains normal glucose tolerance [16]. The pancreatic beta cells release insulin when blood glucose concentrations rise above normal values to allow normal blood glucose levels to be achieved [17]. In a normal pregnancy, insulin requirements are high because of multiple factors, including increased production of placental growth hormone, progesterone, cortisol, prolactin and human placental lactogen, estrogen and tumor necrosis factor $a$

${ }^{\star}$ Correspondence to: Andrea Ciavattini, Department of Clinical Sciences, Unit of Obstetrics and Gynecology Università Politecnica delle Marche, Via Corridoni, 60124 Ancona, Italy, Tel: +39 071596 2053; E-mail: a.ciavattini@univpm.it

Key words: gestational diabetes, risk factors, diagnostic criteria, therapy, physical activity, management, complications

Received: May 02, 2019; Accepted: May 28, 2019; Published: June 03, 2019 
(TNF- $\alpha$ ) and few authors reported that these hormones induce a state of insulin resistance both in vitro and in vivo [17-19].

It is thought that GDM is related to beta cell dysfunction that occurs in the context of insulin resistance through a $67 \%$ reduction in pancreatic beta cell function in women with GDM compared to normal pregnant women [20].

Adipose tissue is an endocrine organ through which the synthesis and secretion of adipocytokines including pro- and anti-inflammatory mediators, such as leptin, adiponectin, and resistin, is well known and therefore obesity and inflammation are the main actors in the development of IR [21]. During normal pregnancy, the secretion of altered adipokines contributes to glucose homeostasis, both through direct mechanisms and therefore through the regulation of insulin secretion and insulin sensitivity, and through indirect mechanisms that refer to inflammation, to the regulation of adipogenesis, chemoattraction of immune cells and subsequent effects on glucose metabolism [22].

Recent studies show changes in adipocytokine concentration levels, identifying low levels of serum adiponectin in women with GDM [23]. The expression of placental adiponectin is also regulated in GDM, suggesting that a reduction of serum adiponectin in GDM is at least partly due to the low placental secretion, opposite to the adipocytes [23]. Low levels of adiponectin aggravate insulin resistance and are correlated with pancreatic beta dysfunction, a characteristic of GDM. High levels of leptin, in GDM women, positively associated with body adiposity and insulin resistance, influences the glucose utilization and the glycogen synthesis. Serum leptin concentrations are directly proportional to fat mass and the reduced reactivity of central leptin or leptin is observed in obesity. From the early stages of pregnancy there is an increase in leptin levels, which implies that the increases are not due only to the increase in maternal weight. It appears that plasma and placental resistin levels in women with GDM are higher than in women not pregnant, although not all the studies confirmed this role. Visfatin, a protein involved in the maturation of beta cells, shows higher concentrations in women with GDM compared to non-GDM women $[21,22]$.

\section{Risk factors for GDM}

Arora D and colleagues showed that it is important to understand which are the main risk factors for GDM in order to improve screening programs and diagnostic accuracy [24]. The most important risk factors for GDM, that affect the pregnant woman, include obesity and maternal overweight (Body Mass Index, BMI > 30, or increase in pregnancy weight over $110 \%$ of ideal body weight) a particular

ethnicity or race, polycystic ovary syndrome (PCOS), prediabetes, any previous history of GDM, any family history of type 2 diabetes, previous history of fetal death, history of childbirth of any macrosomic child weighing $4.5 \mathrm{~kg}$ or more (NICE 2015) and increase of maternal age ( $>25$ years) $[25,26]$. In particular, both obesity at the beginning of pregnancy and an excessive gestational weight gain are significant factors for GDM [27] so the Institute of Medicine (IOM) developed guidelines for adequate weight gain during pregnancy according to pre-pregnant BMI [28]. In fact, overweight may be associated with a rapid increase in insulin resistance leading to the depletion of pancreatic $\beta$-cells, thereby reducing the ability to compensate due to the increasing insulin resistance of pregnancy, and therefore lead to maternal hyperglycemia, hyperinsulinemia and excessive fetal growth. However, as adipose tissue may differ in its functional related to its localization, a recent study has demonstrated that central adiposity is the most important regional deposition of fat connected to GDM [29]. At the present time, it has been shown that GDM is also associated with several conditions, in particular polycystic ovary syndrome, characterized by an association between insulin resistance and hyperandrogenism. The results of the study conducted by Joham et al showed an association between the presence of PCOS and an increase in the prevalence of GDM $(11.2 \%$ compared to $3.8 \%$ of women without polycystic ovaries) and of DM2 (5.1\% compared to $0,3 \%$ of women without polycystic ovaries) [30]. According to Roos n. et al. women with PCOS are more often obese and more commonly subjected to ART (assisted reproduction technology) than women without PCOS ( $60.6 \%$ vs $34.8 \%$ and $13.7 \%$ vs $1.5 \%)$. Other interesting association are also between polycystic ovary, pre- eclampsia and preterm delivery: doubling of the risk of GDM was also observed [31].

\section{Screening and diagnosis of GDM}

According to the screening and diagnosis protocol for GDM, all pregnant women should be evaluated for clinical characteristics, to determine the risk of GDM, and a 50-g oral glucose-challenge test (OGCT), unless they have a low-risk clinical profile. Such assessment usually occurs between $24^{\text {th }}$ and $28^{\text {th }}$ weeks of gestation, followed by an oral glucose tolerance test (100g-OGTT) if the serum glucose concentration at screening is high [32]. However, these criteria are not worldwide accepted; in fact, there are many data that prove a relationship between the maternal hyperglycaemia and the risk for an adverse perinatal outcome, independent of other risk factors, so that support the one-step approach with 75g-OGTT [33]. The American Diabetes Association (ADA) has adopted the IADPSG recommendation [34], while the American College of Obstetricians and Gynecologists (ACOG) continues to favor the traditional two-step approach [35]. In past years, there was significant variation between the criteria for determining abnormal values. In fact, in 1964, the original criteria established for the GDM diagnosis were based on 100-g, 3-h OGTT [36].

In the late '70s, the National Diabetes Data Group (NDDG) criteria of the National Institutes of Health (NIH) set the use of:

fasting plasma glucose level at $105 \mathrm{mg} / \mathrm{dl}$

1- hour plasma glucose level at $190 \mathrm{mg} / \mathrm{dl}$

2- hour plasma glucose level at $165 \mathrm{mg} / \mathrm{dl}$

3- hour plasma glucose level at $145 \mathrm{mg} / \mathrm{dl}$ [37]

Carpenter and Coustan in 1982 made a reduction to the reference values of the OGTT, respectively; fasting plasma glucose level at $95 \mathrm{mg} /$ $\mathrm{dl}$

1-hour plasma glucose level at $180 \mathrm{mg} / \mathrm{dl}$ 2-hour plasma glucose level at $155 \mathrm{mg} / \mathrm{dl}$

\section{3-hour plasma glucose level at $140 \mathrm{mg} / \mathrm{dl}$ [38].}

The HAPO study (Hypoglycemia and Adverse Pregnancy Outcome) conducted in 2008 was the first attempt to bring the agreement back. It was a prospective observational study designed to establish glycemic threshold values with OGTT of $75 \mathrm{~g}$ testing at 24 to 32 weeks of gestation, predictive of maternal and fetal complications: caesarean section, fetal macrosomia, fetal hyperinsulinemia, neonatal morbidity (shoulder dystocia, hypoglycemia, hyperbilirubinemia, respiratory distress) [33] IADSPG (International Association of Diabetes and Pregnancy Study Groups) in 2010 developed new guidelines for one 
universal screening of GDM with $75 \mathrm{~g}$ OGTT at the $24^{\text {th }}$ and $28^{\text {th }}$ week of gestation. It has been proposed the use of cut-off in OGTT, which allowed the identification with an OR of $1.5,1.75$ or 2.0 in the risk of fetal macrosomia, adiposity neonatal and fetal hyperinsulinemia, but the IADPSG expert group concluded that the default value for the OR at the threshold should be 1.75 [39] (Table 1).

Today, the IADPSG criteria allow to identify new cases of GDM, previously considered as normal, by using other criteria preventing the complications due to hyper glycemia [40].

\section{Prevention, therapy and management of GDM}

The prevention has a central role in GDM management, in particular in high-risk women. It has been proved that exercise and healthy diet, before and during early pregnancies, are associated with reduction in GDM risk. In particular, it has been shown a reduction of $51 \%$ in the development of GDM for women who practiced regular recreational physical activity in the year prior to pregnancy and a reduction of $48 \%$ in the development of GDM for women who had recreational physical activity during the first 20 weeks of pregnancy. If these two activities are combined together, a reduction of $60 \%$ of GDM risk has been documented [41]. The beneficial role of physical activity has also been confirmed by the meta-analysis conducted by Tobias DK et al. which indicates that greater total physical activity before pregnancy or at the beginning of pregnancy was significantly associated with a lower risk of GDM [42].

There are also other studies whose results have not shown that physical activity can prevent the appearance of GDM. One of those is The LIMIT study, a randomized trial, conducted in Australia in 2014 to assess whether lifestyle intervention in 2212 overweight or obese women was effective in improving maternal and child health outcomes. Two groups of women were recruited including 1108 women with dietary and lifestyle intervention and 1104 women with standard treatment. This study did not show differences in neonatal (large for gestational age) and maternal outcomes (hypertension, pre-eclampsia and GDM) between the two groups [43]. The controlled randomized UPBEAT (Better Eating and Activity Trial) study in the UK involving 1555 patients of different ethnicities aged over 16 years and BMI $>30 \mathrm{~kg} / \mathrm{m} 2$. This study showed an improvement in glycemic load, a reduction in

weight gain and fat mass in the intervention group but no differences in the incidence of GDM and large-for gestational-age infants between the groups [44]. Another RCT Finnish study, called RADIEL, consisted of examining the effect of mediated physical activity and dietary intervention in 269 women with high-risk GDM or BMI $>30 \mathrm{~kg} / \mathrm{m} 2$ (144 of whom were in the intervention group and 125 in the control group) recruited before the 20th week of pregnancy. In the women involved in the intervention group, the overall incidence of GDM was reduced by $39 \%$ compared to the control group [45]. During the European Multicentre study "DALI Lifestyle Pilot" 150 women were enrolled before the 20th week of gestation, with a high risk of GDM (BMI $>29 \mathrm{~kg} / \mathrm{m} 2)$. Eligible women were randomized into three groups, those following dietary intervention, those following physical activity and those following both (dietary intervention and physical

Table 1: Guidelines for the universal screening of GDM according to IADSPG

\begin{tabular}{|c|c|c|}
\hline OGTT 75 gr & OR 1.75 & OR 2 \\
\hline fasting plasma glucose level & $92 \mathrm{mg} / \mathrm{dl}$ & $95 \mathrm{mg} / \mathrm{dl}$ \\
\hline 1-hour plasma glucose level & $180 \mathrm{mg} / \mathrm{dl}$ & $191 \mathrm{mg} / \mathrm{dl}$ \\
\hline 2-hour plasma glucose level & $153 \mathrm{mg} / \mathrm{dl}$ & $162 \mathrm{mg} / \mathrm{dl}$ \\
\hline
\end{tabular}

activity). The results showed a low fasting glycemia and a lower increase in the gestational weight in the group treated with the diet alone compared to the group treated with physical activity only, however, no differences were found in the frequency of GDM development between the different groups [46].

As physical activity regard, evidences are not enough to suggest that physical activity during pregnancy could be effective in reducing the risk of developing GDM.

Prevention of obesity is a key point in the prevention of GDM; in fact, Sabire NJ et colleagues demonstrated that women with a BMI $\geq$ 30 were more likely to develop gestational diabetes than women with a BMI between 20.0-24.9 [47]. Exercise and weight loss is able to improve insulin sensitivity, decreasing sympathetic activity and /or increasing parasympathetic activity as well as lower resting heart rate and blood pressure [48]. Nutritional therapy is essential in the treatment of GDM, as it helps to avoid an excessive increase in weight, minimizing the onset of macrosomal fetuses and neonatal complications [49].

The American Diabetes Association claims that GDM patients could achieve metabolic control only with nutritional therapy and lifestyle changes [49]. Various methods of dietary counselling may be used in the nutritional therapy in GDM; in particular: i) the glycemic index that is based, mainly, by replacing higher glycemic index foods by lower ones throughout the day; ii) the method based on the energy distribution of macronutrients in meals; and iii) the carbohydrate counting method [50].

However, the first therapeutic approach should be a dietary therapy. In fact, nutrition counselling can optimize maternal and fetal outcomes so it is recommended a minimum of three visits with a dietitian, with the purpose of; a) reach and maintain normoglycemia of the mother: b) prevent ketosis and its effects: c) provide an appropriate increase of gestational based on the index of maternal body mass weight (BMI) d) contribute to normal fetal growth [51,52]. Several authors have studied the better dietary composition [53], recommending high intake of fruit, green leafy vegetables, poultry, fish and whole grain, avoiding high intake of red meat, processed meat, refined grain products, sweets, French fries, sugar-sweetened beverage and pizza, however with a diet based on a nutritional assessment with indications on the dietary intake of reference for all pregnant women; minimum 175 $\mathrm{g}$ of carbohydrates, $71 \mathrm{~g}$ of protein and $28 \mathrm{~g}$ of fiber [52]. Moreover, polyunsatured fat intake may be protective against glucose intolerance in pregnancy, whilst high intake of saturated fat may be detrimental. In fact, it has been demonstrated that elevated circulating fatty acids play a role in GDM development [54]. Furthermore, women with GDM are specifically recommended to follow meal plans with carbohydrate intake distributed throughout the day into 3 small to moderate sized meals and 2-3 snacks [55]. However, it is very important to give individualized nutritional care for women with GDM in order to have better perinatal outcomes [51].

Taking into account what written before, glucose monitoring is very important and the minimum goals for glycaemia are [56]:

- Fasting capillary blood glucose level $95 \mathrm{mg} / \mathrm{dL}$ ( $5.3 \mathrm{mmol} / \mathrm{L}$ )

- One-hour postprandial capillary blood glucose level,140 mg/dL (7.8 $\mathrm{mmol} / \mathrm{L}$ ) or

- Two-hour postprandial capillary blood glucose level ,120 mg/dL (6.7 $\mathrm{mmol} / \mathrm{L})$. 
If medical nutrition therapy and lifestyle cannot reach and maintain the metabolic targets, insulin therapy is the gold standard in the treatment of GDM as it is not able to cross the placenta in a measurable extent, although there is no evidence to support the benefits of any type of insulin or insulin regimen compared to another [56-59]. Insulin therapy should be considered if the plasma glucose goals are not met on two or more occasions during a 1 o 2 weeks follow-up, particularly if there is a clinical or ultrasonographic suspicion of macrosomia [57]. Usually, during pregnancy, a basal/ bolus combination of long and short-acting insulin preparations are used. However, therapy should be individualized and based on local expertise [60]. Human insulin and insulin analogues, such as lispro insulin, aspart and glargine, could be used in pregnancy. Nevertheless, it has been demonstrated that insulin analogues, especially lispro and aspart, may produce better glycemic control with less hypo glycemia risk compared to the use of human insulin [61]. The most used regimen is modified multidose, with a short acting insulin analogue administered before meals as required, and a medium acting insulin at bedtime if fasting blood glucose levels are elevated [61]. The use of metformin has been seen to be associated with a lower risk of neonatal hypoglycemia and a smaller increase in maternal weight compared to insulin, however, it has been shown that metformin may slightly increase the risk of preterm birth [56]. There are many studies on the effectiveness and safety of oral hypoglycemic agents during pregnancy, but only few data are available on long term effects in the offspring [62]. Metformin remains a reasonable second-line choice in women who refuse insulin therapy or in those who will not be able to safely administer insulin [63].

Glyburide also, as well as metformin, crosses the placenta [56]. The results of some studies showed adverse maternal and neonatal outcomes with glyburide compared to insulin in the treatment of GDM and in particular higher rates of hyperbilirubinemia, respiratory distress syndrome, macrosomia, hypoglycemia, hypertension, birth injury $[63,64]$. Since in the results of many studies, treatment with glyburide produces insulin-equivalent outcomes, it should not be recommended as a first-line pharmacological treatment [63]. More randomized controlled trials are required to provide information on long-term follow up on neonatal and cognitive development.

\section{Complication for both the mother and fetus}

The presence of GDM has important implications for both the baby and the mother [65]. As regard baby complication, GDM is associated with a significantly increased risk of macrosomia, shoulder dystocia, birth injuries as well as neonatal hypoglycemia and hypobilurinemia [66]. GDM also adds an intrauterine environmental risk factor to an increased genetic risk for the development of obesity, diabetes and/or metabolic syndrome in childhood [67,68]. Although the underlying mechanism is still unknown, recent findings regarding the effect of GDM on DNA methylation of genes involved in energy metabolism, anti-inflammatory processes, insulin resistance and $\beta$-cell apoptosis could partially explain the increased risk for cardio-metabolic morbidities later in life [69]. Moreover, hyperglycemia modifies the expressions of angiogenesis associated molecules in the trophoblast and pro-inflammation factors such as IL- 6 and TNF- $\alpha$, which adversely affect the intrauterine environment [70,71]. Danielsen I and colleagues demonstrated that not only maternal glycemic state but also maternal glucose intake is associated with offspring adiposity [71].

As regard mother complications, GDM is a strong risk factor for the development of permanent diabetes later in life ( $40 \%$ in 10 subsequent years) [72] and GDM in successive pregnancies (35\%), increasing with the age and weight of the mother [73]. An important intervention on long-term metabolic benefits for both mother and offspring has been attributed to breastfeeding [56]. In the offspring a protective role was seen against excessive fat accumulation, protection against childhood infections, cardiovascular diseases and type 2 diabetes, while in women an association between lactation and low concentrations of glucose and insulin and a better tolerance to glucose was seen [21] and a significant delay in the appearance of type 2 diabetes in women with GDM [74]. Several recent studies have found an association between GDM and several long term complications. Stress urinary incontinence and mixed urinary incontinence [75], doubled risk for overactive bladder during premenopausal period [76] and cardiovascular morbidity [77] are the more significant. So, it is important to measure fasting glucose in the immediate postpartum period in order to identify women with persistent fasting hyperglycemia in the diabetic range [78]. The ADA [79], and the Fifth International Workshop-Conference on Gestational Diabetes Mellitus [80] advised long-term follow- up for women with GDM using a 2-h, 75-g oral glucose tolerance test (OGTT). This longterm follow- up is essential and the reassessment of the glycemic state should be undertaken at least 3 years because a negative postpartum screening test excludes only the presence of type 1 or type 2 diabetes at the time of the test. This long-term follow-up is essential, and reassessment of glycemic status should be undertaken at a minimum of 3 years because a negative postpartum screening test only excludes the presence of type 1 or type 2 diabetes at the time of the test. In 2010, the ADA [81] as well as in 2011 the WHO [82] consistently added HbAlc levels $\geq 6.5 \%$ ( $49 \mathrm{mmol} / \mathrm{mol}$ ) to their diagnostic recommendations of overt diabetes. However, this method is not universally approved because of evidence for large interindividual physiologic variability.

\section{Conclusions}

The findings of this review show how screening, diagnosis and early intervention in the lifestyle, help to better follow the future mother and reduce complications for both the mother and the offspring. Although there are not worldwide-accepted criteria, the IADSPSG criteria should be the preferred international approach. Early identification of these patients is important as they have a higher risk of both maternal and fetal outcomes and treatment should begin as soon as possible.

\section{Conflicts of interest}

None.

\section{References}

1. Poulakos P, Mintziori G, Tsirou E, Taousani E, Savvaki D, et al. (2015) Comments on gestational diabetes mellitus: from pathophysiology to clinical practice. Hormones 14: 335-44. [Crossref]

2. Ferrara A (2007) Increasing prevalence of gestational diabetes mellitus: a public health perspective. Diabetes Care 30: 141-146.

3. American diabetes association (2017) 2 Classification and diagnosis of diabetes. Diabetes care 40: 11-24.

4. Crowther CA, Hiller JE, Moss JR, McPhee AJ, Jeffries WS, et al. (2005) Effect of treatment of gestational diabetes mellitus on pregnancy outcomes. N Engl J Med 352: 2477-86. [Crossref]

5. Leybovitz-Haleluya N, Wainstock T, Landau D, Sheiner E (2018) Maternal gestationa diabetes mellitus and the risk of subsequent pediatric cardiovascular diseases of the offspring: a population- based cohort study with up to 18 years of follow up. Acta Diabetol 55: 1037-1042.

6. Bhowmik B, Afsana F, Ahmed T, Siddiquee T, Ahmed T, et al. (2018) Evaluation of knowledge regarding gestational diabetes mellitus: a Bangladeshi study. Public Health 161: 67-74. [Crossref] 
7. Mijatovic-Vukas J, Capling L, Cheng S, Stamatakis E, Louie J, et al. (2018) Associations of diet and physical activity with risk for gestational diabetes mellitus: a systematic review and meta-analysis. Nutrients 10. [Crossref]

8. Zhang C, Tobias DK, Chavarro JE, Bao W, Wang D, et al. (2014) Adherence to healthy lifestyle and risk of gestational diabetes mellitus: prospective cohort study. BMJ 349: 5450 .

9. DF Diabetes Atlas $8^{\text {th }}$ edition 2017

10. Arora D, Arora R, Sangthong S, Leelaporn W, Sangratanathongchai J (2013) Universal screening of gestational diabetes mellitus: prevalence and diagnostic value of clinical risk factors. J Med Assoc Thai 96: 266-271. [Crossref]

11. Eades CE, Cameron DM, Evans JMM (2017) Prevalence of gestational diabetes mellitus in Europe: A meta-analysis. Diabetes Res Clin Pract 129: 173-181. [Crossref]

12. Solomon CG, Willett WC, Carey VJ, Rich-Edwards J, Hunter DJ, et al. (1997) A prospective study of pregravid determinants of gestational diabetes mellitus. JAMA 278: 1078-83. [Crossref]

13. Magee MS, Walden CE, Benedetti TJ, Knopp RH (1993) Influence of diagnostic criteria on the incidence of gestational diabetes and perinatal morbidity. JAMA 269: 609-615. [Crossref]

14. Hedderson MM, Darbinian JA, Ferrara A (2010) Disparities in the risk of gestationa diabetes by race-ethnicity and country of birth. Paediatr Perinat Epidemiol 24: 441448. [Crossref]

15. Dooley SL, Metzger BE, Cho NH (1991) Influence of race on disease prevalence and perinatal outcome in a U.S. population. Diabetes 40: 25-29. [Crossref]

16. Baz B, Riveline JP, Gautier JF (2016) Endocrinology of pregnancy: Gestational diabetes mellitus: definition, aetiological and clinical aspect. Eur J Endocrinol 174: 43-51.

17. Tieu J, McPhee AJ, Crowther CA, Middleton P, Shepherd E (2017) Screening for gestational diabetes mellitus based on different risk profiles and settings for improving maternal and infant health. Cochrane Database Syst Rev 8. [Crossref]

18. Barbour LA, McCurdy CE, Hernandez TL, Kirwan JP, Catalano PM, et al. (2007) Cellular mechanisms for insulin resistance in normal pregnancy and gestational diabetes. Diabetes Care 30: 112-119.

19. Ryan EA, Enns L (1988) Role of gestational hormones in the induction of insulin resistance. J Clin Endocrinol Metab 67: 341-347.

20. Mirghani DA, Doupis J (2017) Gestational diabetes from A to Z. World J Diabetes 8: 489-511.

21. Vejrazkova D, Vankova M, Lukasova P, Vcelak J, Cirmanova V, et al. (2017) Specific metabolic characteristics of women with former gestational diabetes: the importance of adipose tissue. Physiol Res 66: 349-356. [Crossref]

22. Abell SK, De Courten B, Boyle JA, Teede HJ (2015) Inflammatory and other Biomarkers: Role in pathophysiology and prediction of gestational diabetes mellitus. Int J Mol Sci 16: 13442-13473. [Crossref]

23. Simpson S, Smith L, Bowe J (2018) Placental peptides regulating islet adaptation to pregnancy: clinical potential in gestational diabetes mellitus. Curr Opin Pharmacol 43: 59-65. [Crossref]

24. Arora D, Arora R, Sangthong S, Leelaporn W, Sangratanathongchai J (2013) Universal screening of gestational diabetes mellitus: prevalence and diagnostic value of clinical risk factors. J Med Assoc Thai 96: 266-271. [Crossref]

25. Chen P, Wang S, Ji J, Ge A, Chen C, et al. (2015) Risk factors and management of gestational diabetes. Cell Biochem Biophys 71: 689-694.

26. Gilmartin AB, Ural SH, Repke JT (2008) Gestational diabetus mellitus. Rev Obste Gynecol 1: 129-134.

27. Baci Y, Ustuner I, Keskin HL, Ersoy R, Avsar AF (2013) Effect of maternal obesity and weight gain on gestational diabetes mellitus. Gynecol Endocrinol 29: 133-136.

28. Institute of Medicine (US) and National Research Council (US) Committee to Reexamine IOM Pregnancy Weight Guidelines (2009) Weight Gain During Pregnancy: Reexamining the Guidelines.

29. Sommer C, Morkrid K, Jenum AK, Sletner L, Mosdol A, et al. (2014) Weight gain, tota fat gain and regional fat gain during pregnancy and the association with gestational diabetes: a population-based cohort study. Int J Obes (Lond) 38: 76-81. [Crossref]

30. Joham AE, Ranasinha S, Zoungas S, Moran L, Teede HJ (2014) Gestational diabetes and type 2 diabetes in reproductive-aged women with polycystic ovary syndrome. $J$ Clin Endocrinol Metab 99: 447-452. [Crossref]
31. Roos N, Kieler H, Sahlin L, Ekman-Ordeberg G, Falconer H, et al. (2011) Risk of adverse pregnancy outcomes in women with polycystic ovary syndrome: population based cohort study. BMJ 343: 6309 .

32. Hod M, Carrapato M, Working Group on Diabetes and Pregnancy (2002) Diabetes and pregnancy. update and guidelines. European Association of Perinatal Medicine (Google scholar)

33. HAPO Study Cooperative Research Group, Metzger BE, Lowe LP, Dyer AR, Trimble ER, et al. (2008) Hyperglycemia and adverse pregnancy outcomes. N Engl J Med 358: 1991-2002.

34. Basevi V, Di Mario S, Morciano C, Nonino F, Magrini N (2011) Comment on: American diabetes association. Standards of medical care in diabetes--2011. Diabetes Care 2011;34(supplement 1): S4 Diabetes Care 34: e53. [Crossref]

35. Committee on Practice Bulletins-Obstetrics (2018) ACOG Practice Bulletin No. 190: Gestational diabetes mellitus. Obstet Gynecol 131: e49-e64. [Crossref]

36. Agarwal MM (2018) Consensus in gestational diabetes mellitus; looking for the holy grail. J Clin Med 7. [Crossref]

37. National diabetes data group (1979) Classification and diagnosis of diabetes mellitus and other categories of glucose intolerance. Diabetes 28: 1039-1057. [Crossref]

38. Carpenter MW, Coustan DR (1982) Criteria for screening tests for gestational diabetes. Am J Obstet Gynecol 144: 768-773.

39. International association of diabetes and pregnancy study groups consensus $P$, Metzger BE, Gabbe SG, Persson B, Buchanan TA, et al. (2010) International association of diabetes and pregnancy study group recommendation on the diagnosis and classification of Hyper glycemia in pregnancy. Diabetes Care 33: 676-682. [Crossref]

40. Reyes-Muñez E, Parra A, Castillo-Mora A, Ortega-Gonzales C (2012) Effect of the diagnostic criteria of the International association of diabetes and pregnancy study groups diagnostic criteria on the prevalence of gestational diabetes in urban Mexican women: a cross-sectional study. Endocrine Practice 18: 146-51. [Crossref]

41. Dempsey JC, Butler CL, Sorensen TK, Lee IM, Thompson ML, et al. (2004) A casecontrol study of maternal recreational physical activity and risk of gestational diabetes mellitus. Diabetes Res Clin Pract 66: 203-215. [Crossref]

42. Tobias DK, Zhang C, van Dam RM, Bowers K, Hu FB (2011) Physical activity before and during pregnancy and risk of gestational diabetes mellitus: a meta-analysis. Diabetes Care 34: 223-229. [Crossref]

43. Dodd JM, Turnbull D, McPhee AJ, Deussen AR, Grivell RM, et al. (2014) Antenatal lifestyle advice for women who are overweight or obese: LIMIT randomised trial. BMJ 348: g1285.

44. Poston L, Bell R, Croker H, Flynn AC, Godfrey KM, et al. ( 2015) Effect of a behavioural intervention in obese pregnant women (the UPBEAT study): a multicentre, randomised controlled trial. Lancet Diabetes Endocrinol 3: 767-777. [Crossref]

45. Koivusalo SB, Rono K, Klemetti MM, Roine RP, Lindstrom J, et al. (2016) Gestational diabetes mellitus can be prevented by lifestyle intervention: the Finnish Gestational Diabetes Prevention Study (RADIEL): a randomized controlled trial. Diabetes Care 39: 24-30. [Crossref]

46. Simmons D, Jelsma JG, Galjaard S, Devlieger R, van Assche A, et al. (2015) Results from a European multicentre randomized trial of physical activity and/or healthy eating to reduce the risk of gestational diabetes mellitus: the DALI Lifestyle Pilot. Diabetes Care 38: 1650-1656.

47. Sabire NJ, Jolly M, Harris JP, Wadsworth J, Joffe M, et al. (2001) Maternal obesity and pregnancy outcome: a study of 287,213 pregnancies in London. Int J Obes Relat Metab Disord 25: 1175-1182. [Crossref]

48. Bung P, Artal R, Khodiguian N (1993) Regular exercise therapy in disorders of carbohydrate metabolism in pregnancy--results of a prospective, randomized longitudinal study. Geburtshilfe Frauenheilkd 53: 188-193. [Crossref]

49. American diabetes association (2012) Diagnosis and classification of diabetes mellitus. Diabetes Care 35: 64-71.

50. Balas-Nakash M, Rodríguez-Cano A, Muñoz-Manrique C, Vásquez-Peña P, PerichartPerera O (2010) Adherence to a medical nutrition therapy program in pregnant women with diabetes, measured by three methods, and its association with glycemic control. Rev Invest Clin 62: 235-243. [Crossref]

51. Reader D, Splett P, Gunderson EP, Diabetes care and education dietetic practice group (2006) Impact of gestational diabetes mellitus nutrition practice guidelines implemented by registered dietitians on pregnancy outcomes. J Am Diet Assoc 106: 1426-1433. [Crossref] 
52. Durnwal C (2018) Gestational diabetes mellitus: Glycemic control and maternal prognosis. Up To Date.

53. Hernandez TL, Anderson MA, Chartier-Logan C, Friedman JE, Barbour LA (2013) Strategies in the nutritional management of gestational diabetes. Clin Obstet Gynecol 56: 803-815.

54. Chen X, Scholl TO, Leskiw M, Savaille J, Stein TP (2010) Differences in maternal circulating fatty acid composition and dietary fat intake in women with gestationa diabetes mellitus or mild gestational hyperglycemia. Diabetes Care 33: 2049-2054. [Crossref]

55. Franz MJ, Boucher JL, Green-Pastors J, Powers MA (2008) Evidence-based nutrition practice guidelines for diabetes and scope and standards of practice. J Am Diet Assoc 108: S52-S58

56. American diabetes association (2018) 13. Management of diabetes in pregnancy: Standards of medical care in diabetes-2018. Diabetes Care 41: S137-S143. [Crossref]

57. Rodbard HW, Blonde L, Braithwaite SS, Brett EM, Cobin RH, et al. (2007) American association of clinical endocrinologists medical guidelines for clinical practice for the management of diabetes mellitus. Endocr Pract 13: 1-68. [Crossref]

58. American diabetes association (2004) Gestational diabetes mellitus. Diabetes Care 27: $88-90$

59. Hod M, Kapur A, Sacks DA, Hadar E, Agarwal M, et al. (2015) The International federation of gynecology and obstetrics (FIGO) Initiative on gestational diabete mellitus: A pragmatic guide for diagnosis, management, and care. Int J Gynaecol Obstet 131: 173-211.

60. McElduff A, Moses RG (2012) Insulin therapy in pregnancy. Endocrinol Metab Clin North Am 41: 161-173. [Crossref]

61. Durnwald CP (2013) Insulin analogues in the treatment of gestational diabetes mellitus. Clin Obstet Gynecol 56: 816-826. [Crossref]

62. Niromanesh S, Alavi A, Sharbaf FR, Amjadi N, Moosavi S, et al. (2012) Metformin compared with insulin in the management of gestational diabetes mellitus: a randomized clinical trial. Diabetes Res Clin Pract 98: 422-429. [Crossref]

63. Committee on practice bulletins-Obstetrics (2017) ACOG Practice Bulletin Number 180: Gestational diabetes mellitus. Obstet Gynecol 130: e17-e37.

64. Castillo CW, Boggess K, Stürmer T, Brookhart MA, Benjamin DK Jr, et al. (2015) Association of adverse pregnancy outcomes with glyburide vs Insulin in women with gestational diabetes. JAMA Pediatr 169: 452-458.

65. Hoffman L, Nolan C, Wilson JD, Oats JJ, Simmons D (1998) Gestational diabetes mellitus- management guidelines. The Australasian diabetes in pregnancy society. Med J Aust 169: 93-97.

66. Hod M, Merlob P, Friedman S, Schoenfeld A, Ovadia J (1991) Gestational diabetes mellitus: a survey of perinatal complications in the 1980s. Diabetes 40: 74-78.

67. Silverman BL, Metzger BE, Cho NH, Loeb CA (1995) Impaired glucose tolerance in adolescent offspring of diabetic mothers: Relationship to fetal hyperinsulinism. Diabetes Care 18: 611-617.
68. Boney CM, Verma A, Tucker R, Vohr BR (2005) Metabolic syndrome in childhood: association with birth weight, maternal obesity, and gestational diabetes mellitus. Pediatrics 115: e290-e296. [Crossref]

69. Ruchat SM, Houde AA, Voisin G, St-Pierre J, Perron P, et al. (2013) Gestational diabetes mellitus epigenetically affects genes predominantly involved in metabolic diseases. Epigenetics 8: 935-943. [Crossref]

70. Chang SC, Vivian Yang WC (2013) Hyperglycemia induces altered expressions of angiogenesis associated molecules in the trophoblast. Evid Based Complement Alternat Med 2013: 457971. [Crossref]

71. Danielsen I, Granström C, Haldorsson T, Rytter D, Hammer Bech B, et al. (2013) Dietary glycemic index during pregnancy is associated with biomarkers of the metabolic syndrome in offspring at age 20 years. PLoS One 8: e64887. [Crossref]

72. Lauenborg J, Hansen T, Jensen DM, Vestergaard H, Molsted-Pedersen L, et al. (2004) Increasing incidence of diabetes after gestational diabetes: a long- term follow-up in a Danish population. Diabetes Care 27: 1194-1199.

73. Moses RG (1996) The recurrence rate of gestational diabetes in subsequent pregnancies. Diabetes Care 19: 1348-1350.

74. Ziegler AG, Wallner M, Kaiser I, Rossbauer M, Harsunen MH, et al. (2012) Long-term protective effect of lactation on the development of type 2 diabetes in women with recent gestational diabetes mellitus. Diabetes 61: 3167-3171. [Crossref]

75. Fehniger JE, Brown JS (2014) Gestational diabetes is associated with increased risk of urinary incontinence up to 2 years postpartum. Evid Based Nurs 17: 10-11. [Crossref]

76. Tettamanti G, Iliadou AN, Pedersen NL, Bellocco R, Altman D (2013) Association between gestational diabetes mellitus and subsequent overactive bladder among premenopausal female twins. BJOG 120: 1289-1295. [Crossref]

77. Kessous R, Shoham-Vardi I, Pariente G, Sherf M, Sheiner E (2013) An association between gestational diabetes mellitus and long-term maternal cardiovascular morbidity. Heart 99: 1118- 1121.

78. Heatley E, Middleton P, Hague W, Crowther C (2013) The DIAMIND study: postpartum SMS reminders to women who have had gestational diabetes mellitus to test for type 2 diabetes: a randomised controlled trial - study protocol. BMC Pregnancy Childbirth 13: 92. [Crossref]

79. American Diabetes Association (2019) 14. Management of diabetes in pregnancy: Standards of medical care in diabetes-2019. Diabetes Care 42: S165-S172. [Crossref]

80. Metzger BE, Buchanan TA, Coustan DR, de Leiva A, Dunger DB, et al. (2007) Summary and recommendations of the fifth international workshop-conference on gestational diabetes mellitus. Diabetes Care 30: S251-S260. [Crossref]

81. World Health Organization (2011) Use of glycated haemoglobin (HbA1c) in the diagnosis of diabetes mellitus. Abbreviated Report of a WHO Consultation.

82. Picon MJ, Murri M, Munoz A, Fernandez-Garcia JC, Gomez-Huelgas R, et al. (2012) Hemoglobin A1c versus oral glucose tolerance test in postpartum diabetes screening. Diabetes Care 35:1648-1653.

Copyright: (C2019 Alia S. This is an open-access article distributed under the terms of the Creative Commons Attribution License, which permits unrestricted use, distribution, and reproduction in any medium, provided the original author and source are credited. 